\title{
Rufuslactone, a New Antifungal Sesquiterpene from the Fruiting Bodies of the Basidiomycete Lactarius rufus
}

\author{
Du-Qiang Luo, Fei Wang, Xiao-Ying Bian, Ji-Kai Liu
}

Received: May 11, 2005 / Accepted: July 4, 2005

(C) Japan Antibiotics Research Association

\begin{abstract}
A new lactarane sesquiterpene, rufuslactone (1), was isolated from the fruiting bodies of the basidiomycete Lactarius rufus. Rufuslactone (1) is an isomer of a previously described lactarane 3,8-oxa-13hydroxylactar-6-en-5-oic acid $\gamma$-lactone (2) from Lactarius necatar. Its structure was elucidated on the basis of spectroscopic data. Rufuslactone (1) showed antifungal properties against plant pathogenic fungi.
\end{abstract}

Keywords Lactarius rufus, basidiomycete, lactarane sesquiterpene, rufuslactone, antifungal agent

\section{Introduction}

Large fungi of the genus Lactarius belong to subdivision Basidiomycotina, order Agaricales, family Russulaceae in Whittaker's kingdom of fungi [1]. They are important symbionts, forming mycorrhiza with higher plants which explains in some cases their preference for growing among certain kinds of trees. The name Lactarius has its origin in the fact that when the fruiting bodies are damaged, they exude a milky cellular juice, namely, lactate. This feature easily allows one to distinguish a Lactarius species from a congener Russula species or other similar mushrooms.

The fungal subdivision Basidiomycotina produces many toxic sesquiterpenes derived from the protoilludane skeleton. Rearrangements and transformation of this skeleton result in a multitude of compounds. Fungal sesquiterpenes formed via the humulane-protoilludane biosynthetic pathway are characteristic for the subdivision
Basidiomycotina [2]. Fungi of the genus Lactarius have been shown to be a good source of bioactive secondary metabolites. Uvidin A, a new fatty acid ester of a drimane sesquiterpene from L. uvidus showed insect antifeedant and cytotoxic activities [3]. The esterification of various sesquiterpenoid alcohols of Lactarius origin with $\mathrm{N}$ benzoyl-[2R,3S]-phenylisoserine (side chain of Taxol) produced compounds whose antifeedant properties against storage pests Tribolium confusum, Trogoderma granarium and Sitophylus granarius were demonstrated [4]. Daniewski et al. also reported that 3,8-oxa-13-hydroxylactar-6-en-5oic-acid $\gamma$-lactone was a good deterrent against insects [5]. Antiviral activities in vitro were reported for $\mathrm{N}$ benzoylphenylisoserinates of Lactarius sesquiterpenoid alcohols [6]. 2-Geranylgeranyl-1,4-dihydroxybenzene isolated from the fruiting bodies of Lactarius lignyotus was highly active in the brine shrimp test. It showed significant inhibitory activity on DNA, RNA, and protein synthesis in HeLa and HL-60 cell lines [7]. Recently, a green pigment blennione and a red pigment lilacinone were isolated from Lactarius blennius and Lactarius lilacinus, respectively [8, 9].

During continuing research on bioactive metabolites of Lactarius and Russula sp. in Yunnan Province of China [10 14], the chemical constituents of the fruiting bodies of Lactarius rufus were investigated. This report deals with the isolation and structure elucidation of a new lactarane sesquiterpene, rufuslactone (1) and its antifungal activities against phytopathogenic fungi.

D.-Q. Luo: College of Plant Protection, Northwest Sci-Tech University of Agriculture and Forestry, Yangling 712100, China
J.-K. Liu (Corresponding author), D.-Q. Luo, F. Wang, X.-Y. Bian: Kunming Institute of Botany, the Chinese Academy of Sciences, Kunming 650204, China, E-mail: jkliu@mail.kib.ac.cn 


\section{Experimental}

\section{General}

Optical rotations were measured on a Horiba SEPA-300 polarimeter. UV spectra were recorded on a Shimadzu UV2401PC spectrophotometer. IR spectra were obtained with a Tensor 27 with $\mathrm{KBr}$ pellets. NMR spectra were recorded on Bruker AV-400 and Bruker DRX-500 spectrometers in $\mathrm{CDCl}_{3}$ with TMS as an internal standard. EI-MS were recorded with a VG Autospec-3000 spectrometer. HRESIMS were recorded with an API QSTAR Pulsar 1 spectrometer.

Silica gel (200 300 mesh, Qingdao Marine Chemical Inc., China) and Sephadex LH-20 (Amersham Biosciences, Sweden) were used for column chromatography. Fractions were monitored by TLC and spots were visualized by heating silica gel plates sprayed with $10 \% \mathrm{H}_{2} \mathrm{SO}_{4}$ in ethanol.

\section{Material}

The fresh fruiting bodies of Lactarius rufus were collected at Ailao Mountain, Yunnan Province, China in July 2003 and identified by Prof. Mu Zang, Kunming Institute of Botany, the Chinese Academy of Sciences. A voucher specimen is deposited at the Herbarium of Kunming Institute of Botany, the Chinese Academy of Sciences.

\section{Extraction and Isolation}

The fresh fruiting bodies of $L$. rufus $(7 \mathrm{~kg})$ were extracted with $95 \%$ aq. EtOH (30 liters). The EtOH soln. was evaporated in vacuo to give the extract $(512 \mathrm{~g})$. The $\mathrm{EtOH}$ extract was extracted with $\mathrm{CHCl}_{3}$, and $\mathrm{CHCl}_{3} / \mathrm{MeOH}(1: 1$, $\mathrm{v} / \mathrm{v})$ three times, respectively, at room temperature. The combined $\mathrm{CHCl}_{3}$ and $\mathrm{CHCl}_{3} / \mathrm{MeOH}(1: 1, \mathrm{v} / \mathrm{v})$ extracts were concentrated in vacuo to yield crude residues weighing $84 \mathrm{~g}$ and $30 \mathrm{~g}$ respectively. The $\mathrm{CHCl}_{3}$ extract was subjected to column chromatography eluting with $\mathrm{CHCl}_{3} / \mathrm{MeOH}$ from 100:0 (v/v) to 50:50 (v/v) to give 10 fractions. The fraction eluted by $\mathrm{CHCl}_{3} / \mathrm{MeOH}(98: 2, \mathrm{v} / \mathrm{v})$ was concentrated to give a solid $(150 \mathrm{mg})$ which was further purified by Sephadex LH-20 column chromatography, eluting with $\mathrm{CHCl}_{3} / \mathrm{MeOH}(1: 1, \mathrm{v} / \mathrm{v})$ to afford compound $\mathbf{1}(20 \mathrm{mg}$ ).

\section{Physico-chemical Properties}

Rufuslactone (1): colorless crystals, m.p. $154 \sim 156^{\circ} \mathrm{C}$ $\left(\mathrm{CHCl}_{3}\right) \cdot[\alpha]_{\mathrm{D}}^{22.6}-5.87\left(c 0.24, \mathrm{CHCl}_{3}\right) . \mathrm{UV} \lambda_{\max }\left(\mathrm{CHCl}_{3}\right)$ $239 \mathrm{~nm}$. IR (KBr) 3417, 3331, 2965, 2936, 2907, 1732, 1684, 1464, 1382, 1365, 1347, 1256, 1233, 1142, 1113, $1032 \mathrm{~cm}^{-1}$. EI-MS m/z 248 (M, 100), 233 (M-Me, 37),
$230\left(\mathrm{M}-\mathrm{H}_{2} \mathrm{O}, 17\right), 219$ (8), 215 (11), 206 (33), 204 (51), 191 (27), 187 (20), 175 (14), 170 (47), 161 (25), 159 (28), 152 (64), 122 (93). HRESI-MS $m / z 249.1487\left[(\mathrm{M}+1)^{+}\right.$, calcd. for $\mathrm{C}_{15} \mathrm{H}_{21} \mathrm{O}_{3}$ 249.1490].

\section{Mycelial Growth Inhibition Test}

Rufuslactone dissolved in DMSO was tested for antifungal activity in vitro by a Poison Food Technique. Potato dextrose agar (PDA) medium was used as the medium for all test fungi. The test pathogenic fungi were Alternaria brassicae Cav, Botrytis cinerea Pers. ex Tris., Fusarium graminearum Schw and Alternaria alternata (Fries) Keissler.

The medium incorporating test compound $\mathbf{1}$ at concentration of $100 \mu \mathrm{g} / \mathrm{ml}$ (DMSO concentration 1\%) was inoculated at the centre with agar discs of the test fungi ( $4 \mathrm{~mm}$ diameter). Three replicate plates for each fungus were incubated at $26( \pm 2)^{\circ} \mathrm{C}$. Control plates containing media mixed with DMSO (DMSO concentration 1\%) were included. After incubation for $2 \sim 6$ days until the fungal growth in the control dishes was almost complete, the mycelial growth of fungi $(\mathrm{mm})$ in both treated $(T)$ and control $(C)$ Petri dishes was measured diametrically in three different directions. The percentage of growth inhibition $(I)$ was calculated using the formula:

$$
\mathrm{I}(\%)=[(C-T) / C] \times 100
$$

The corrected inhibition (IC) was then calculated as follow:

$$
\mathrm{IC}=[(I-C F) /(100-C F)] \times 100
$$

Where $C F=\left[\left(90-C_{0}\right) / C_{0}\right] \times 100 ; 90$ is the diameter $(\mathrm{mm})$ of the Petri dish, and the $C_{0}$ is the growth $(\mathrm{mm})$ of the fungus in the control.

Analysis of variance was performed on the data with the PROCGLM procedure (SAS Institute, Cary, NC, USA). If $P>F$ was less than 0.01 , means were separated with the least significant different (LSD) test at the $P=0.05$ level.

\section{Results and Discussion}

Compound 1 was obtained as colorless crystals. The molecular formula of $\mathbf{1}$ was determined to be $\mathrm{C}_{15} \mathrm{H}_{20} \mathrm{O}_{3}$ on the basis of HRESI-MS [M+1] ${ }^{+} \mathrm{m} / z 249.1487$ (calcd. for $\mathrm{C}_{15} \mathrm{H}_{21} \mathrm{O}_{3} 249.1490$ ) and its ${ }^{13} \mathrm{C}-\mathrm{NMR}$ (DEPT) spectrum including signals for a carbonyl carbon $(\delta$ 175.8), two quaternary carbons $(\delta 74.7,36.8)$, two olefinic carbons $(\delta$ $160.1,123.4)$, three methine carbons $(\delta 67.1,49.1,46.0)$, four methylene carbons $(\delta 71.7,45.3,45.1,34.7)$ and three methyl carbons $(\delta 31.0,29.1,26.4)$. Its IR spectrum showed bands $3417 \mathrm{~cm}^{-1}(\mathrm{OH})$ and $1732 \mathrm{~cm}^{-1}$, typical for a 
Table 1 The ${ }^{1} \mathrm{H}$ - and ${ }^{13} \mathrm{C}-\mathrm{NMR}$ data for $\mathbf{1 ,} \mathbf{2}$ and $\mathbf{3}$

\begin{tabular}{|c|c|c|c|c|c|c|}
\hline \multirow{2}{*}{$\begin{array}{c}\text { No. } \\
1\end{array}$} & \multicolumn{2}{|l|}{1} & \multicolumn{2}{|l|}{$2^{5)}$} & \multicolumn{2}{|c|}{$3^{15)}$} \\
\hline & $1.60(\mathrm{dd}, 11.6,8.8)$ & $45.1(t)$ & $1.40(\mathrm{dd}, 12.0,8.0)$ & $31.2(\mathrm{t})$ & $1.60(\mathrm{~m})$ & $45.9(t)$ \\
\hline & $1.09(t, 11.8)$ & & $0.90(\mathrm{~m})$ & & $1.23(\mathrm{~m})$ & \\
\hline 2 & $2.62(\mathrm{~m})$ & 49.1 (d) & $2.82(\mathrm{td}, 11.6,11.6,8.0)$ & $54.1(d)$ & $2.65(\mathrm{~m})$ & $50.0(d)$ \\
\hline 3 & - & 74.7 (s) & - & 80.7 (s) & - & 74.9 (s) \\
\hline \multirow[t]{2}{*}{4} & 2.59 (brd, 18.7) & $34.7(t)$ & $2.44(d, 18.0)$ & $42.0(t)$ & $2.61(d, 19.2)$ & $35.2(\mathrm{t})$ \\
\hline & 2.48 (brd, 18.7) & & $2.34(d, 18.0)$ & & $2.46(d, 19.2)$ & \\
\hline 5 & - & 175.8 (s) & - & $172.6(\mathrm{~s})$ & - & 172.5 (s) \\
\hline 6 & - & $123.4(\mathrm{~s})$ & - & $124.8(\mathrm{~s})$ & - & 126.3 (s) \\
\hline 7 & - & $160.1(\mathrm{~s})$ & - & $165.6(\mathrm{~s})$ & - & 159.6 (s) \\
\hline 8 & $4.04(d, 3.3)$ & $67.1(d)$ & $4.61(d, 7.1)$ & 74.6 (d) & $4.21(d, 3.2)$ & 66.1 (d) \\
\hline 9 & $2.82(\mathrm{~m})$ & $46.0(d)$ & $3.33(\mathrm{~m})$ & $55.9(d)$ & $2.86(\mathrm{~m})$ & 47.8 (d) \\
\hline \multirow[t]{2}{*}{10} & $1.46(d d, 11.5,6.3)$ & $45.3(t)$ & $1.44(\mathrm{~m})$ & $40.0(t)$ & $1.39(\mathrm{~m})$ & $45.4(t)$ \\
\hline & 0.97 (overlapped) & & $0.90(\mathrm{~m})$ & & $1.23(\mathrm{~m})$ & \\
\hline 11 & - & 36.8 (s) & - & 47.0 (s) & - & 37.3 (s) \\
\hline 12 & $1.22(\mathrm{~s})$ & $31.0(q)$ & $1.48(\mathrm{~s})$ & $29.1(q)$ & $1.24(\mathrm{~s})$ & $34.1(q)$ \\
\hline \multirow[t]{2}{*}{13} & 4.88 (brd, 17.4) & $71.7(\mathrm{t})$ & $4.83(d, 17.6)$ & $71.5(t)$ & - & $108.1(\mathrm{~s})$ \\
\hline & $4.53(\mathrm{brd}, 17.4)$ & & $4.74(d, 17.6)$ & & & \\
\hline 14 & $0.95(s)$ & $26.4(q)$ & $1.00(\mathrm{~s})$ & $27.0(q)$ & 0.99 (s) & $29.3(q)$ \\
\hline 15 & 0.98 (s) & $29.1(q)$ & 0.98 (s) & $27.2(q)$ & 0.97 (s) & $26.8(q)$ \\
\hline 16 & - & - & - & - & $1.98(\mathrm{~m})$ & $30.3(t)$ \\
\hline 17 & - & - & - & - & $0.82(t, 7.3)$ & 7.9 (q) \\
\hline
\end{tabular}

$\mathbf{1}$ and $\mathbf{2}$ were measured in $\mathrm{CDCl}_{3}, \mathbf{3}$ in acetone- $d_{6}$. Coupling constants are given in $\mathrm{Hz}$.
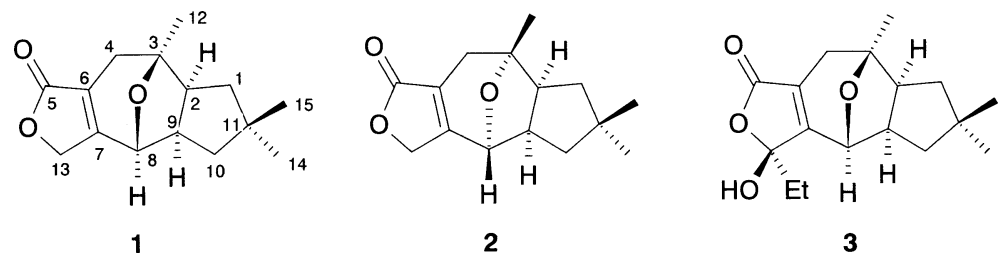

Fig. 1 Structures of $\mathbf{1}, \mathbf{2}$ and $\mathbf{3}$.

lactone. The ${ }^{1} \mathrm{H}$ - and ${ }^{13} \mathrm{C}$-NMR spectra (Table 1) of $\mathbf{1}$ were similar to those of $\mathbf{2}$ and $\mathbf{3}$ [5, 15], which suggested these compounds possess the same lactarane skeleton. The key differences were that $\delta_{\mathrm{C}}$ for carbons 3 and 8 in the spectrum of 2 (80.7 and $74.6 \mathrm{ppm}$ ) are shifted downfield compared to those of $\mathbf{1}$ (74.7 and $67.1 \mathrm{ppm}$, respectively) [5]. This characteristic difference was caused by different configurations of the internal ether between C-3 and C-8 in $\mathbf{1}$ and $\mathbf{2} . \mathbf{1}$ is an isomer of a previously described lactarane 3,8-oxa-13-hydroxylactar-6-en-5-oic acid $\gamma$-lactone (2) from Lactarius necatar. The distinct differences between $\mathbf{1}$ and 3 are that: the hydroxy and the ethyl groups at $\mathrm{C}-13$ of $3\left[\delta_{\mathrm{H}} 1.98\left(2 \mathrm{H}, \mathrm{m},-\mathrm{CH}_{2}-, \mathrm{H}-16\right), 0.82\left(3 \mathrm{H}, \mathrm{t},-\mathrm{CH}_{3}, \mathrm{H}-\right.\right.$ $17) ; \delta_{\mathrm{C}} 30.3$ (t, C-16), 7.9 (q, C-17), $\left.108.1(\mathrm{~s}, \mathrm{C}-13)\right]$ are absent in $1\left[\delta_{\mathrm{H}} 4.88\right.$ (brd, $J=17.4 \mathrm{~Hz}, \mathrm{H}-13 \mathrm{a}$ ), 4.53 (brd,
$J=17.4 \mathrm{~Hz}, \mathrm{H}-13 \mathrm{~b}$ ); $\delta_{\mathrm{C}} 71.7$ (t, C-13)] [15]. The HMBC spectra (Fig. 2) of 1 demonstrated the following key correlations: H-8 and C-2, C-6, C-13; H-12 and C-2, C-4; $\mathrm{H}-9$ and $\mathrm{C}-7$; H-13 and $\mathrm{C}-6$, which were well consisted with the lactarane skeleton. From a Dreiding model, it was evident that the formation of an internal ether between C-3 and C-8 required the bridge-head protons at C-2 and C-9 to be cis. The proposed biosynthesis [16] of the lactarane skeleton indicated the protons at C-2 and C-9 to be $\alpha$ configuration. The small value of the coupling constant $(J=3.3 \mathrm{~Hz})$ demonstrated a syn quasiequatorial orientation of H-8 and H-9 [17], as judged from the Karplus curves. The NOE spectra (Fig. 2) of $\mathbf{1}$ showed significant correlations between $\mathrm{H}-8$ and $\mathrm{H}-9, \mathrm{H}-2$ and $\mathrm{H}-12$, which further confirmed these protons were to be syn. Thus, H-8, 


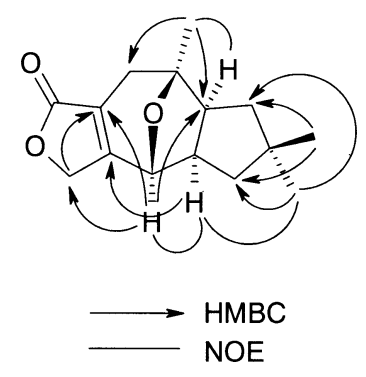

Fig. 2 Key correlations of $\mathrm{HMBC}$ and NOE.

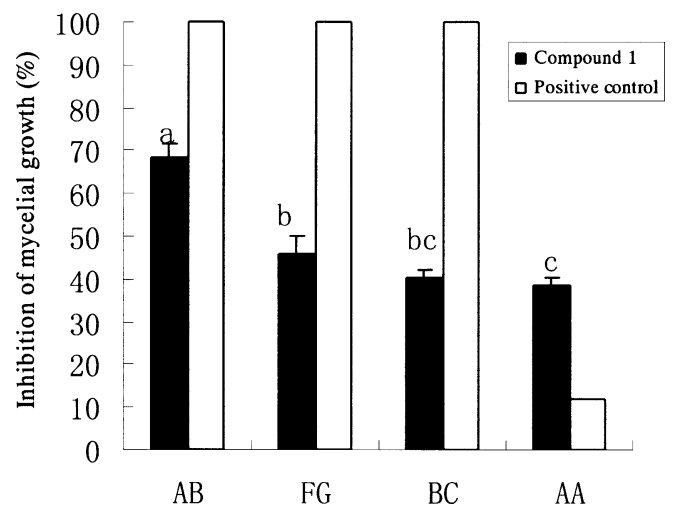

Fig. 3 Antifungal activity spectra of compound $\mathbf{1}$ and positive control (carbendazim) at $100 \mu \mathrm{g} / \mathrm{ml}$ against four phytopathogenic fungi. AB: Alternaria brassicae; FG: Fusarium graminearum; BC: Botrytis cinerea; AA: Alternaria alternata. Error bars represent the standard error of the mean of three replicates. Means followed by the same letter are not significantly different $(P=0.05)$ according to the least significantly difference test.

H-9, and H-2 were all syn to each other but anti to the internal ether. In light of the evidences mentioned above, the structure of $\mathbf{1}$ was therefore elucidated as shown in Fig. 1 and named rufuslactone.

Compound 1 was found to inhibit the mycelial growth of some plant pathogenic fungi in vitro (Fig. 3). Alternaria brassicae was the most sensitive to compound $\mathbf{1}$, and its mycelial growth inhibition was 68.3 at $100 \mu \mathrm{g} / \mathrm{ml}$. To evaluate the fungicidal activity of compound 1, this compound and the commercial fungicide carbendazim were compared under the same assay conditions at $100 \mu \mathrm{g} / \mathrm{ml}$. We found that carbendazim was more effective at inhibiting the mycelial growth of test fungi except for A. alternata. The growth of $A$. alternata was almost unaffected by carbendazim, while $100 \mu \mathrm{g} / \mathrm{ml}$ of compound $\mathbf{1}$ inhibited the growth by $38.9 \%$.

Acknowledgements This project was supported by the National Natural Science Foundation of China (30470027 and 300225048).
References

1. Whitthaker RH. New concepts of kingdoms of organisms. Science 163: 150-160 (1969)

2. Abraham WR. Bioactive sesquiterpenes produced by fungi: are they useful for humans as well? Cur Med Chem 8: 583606 (2001)

3. Garlaschelli L, Mellerio G, Vidari G, Vita-Finiz P. New fatty acid esters of drimane sesquiterpenes from Lactarius uvidus. J Nat Prod 57: 905-910 (1994)

4. Kopczacki P, Gumulka M, Masnyk M, Grabarczyk H, Nowak G, Daniewski WM. Synthesis and antifeedant properties of $N$-benzoylphenylisoserinates of Lactarius sesquiterpenoid alcohols. Phytochemistry 58: 775-787 (2001)

5. Daniewski WM, Gumulka M, Pankowska E, Ptaszynska K, Bloszyk E, Jacobsson U, Norin T. 3,8-ethers of lactarane sesquiterpenes. Phytochemistry 32: 1499-1502 (1993)

6. Krawczyk E, Luczak M, Kobus M, Banka D, Daniewski W. Antiviral activity of N-benzoylphenylisoserinates of Lactarius sesquiterpenoid alcohols in vitro. Planta Med 69: 552-554 (2003)

7. Vidari G, Vita-Finzi P, Zanocchi AM, Noy GP. A bioactive tetraprenylphenol from Lactarius lignyotus. J Nat Prod 58: 893-896 (1995)

8. Spiteller P, Steglich W. Blennione, a green aminobenzoquinone derivative from Lactarius blennius. J Nat Prod 65: 725-727 (2002)

9. Spiteller P, Arnold N, Spiteller M, Steglich W. Lilacinone, a red aminobenzoquinone pigment from Lactarius lilacinus. J Nat Prod 66: 1402-1403 (2003)

10. Tan JW, Dong ZJ, Liu JK. New terpenoids from basidiomycetes Russula lepida. Helv. Chim. Acta 83: 3191-3197 (2000)

11. Tan JW, Dong ZJ, Liu JK. A new sesquiterpenoid from fruiting bodies of Russula lepida. Acta Bot Sin 43: 329-330 (2001)

12. $\mathrm{Hu} \mathrm{L}$, Liu JK. The first humulene type sesquiterpene from Lactarius hirtipes. Z Naturforsch 57c: 571-574 (2002)

13. Tan JW, Dong ZJ, Hu L, Liu JK. Lepidamine, the first aristolane-type sesquiterpene alkaloid from the basidiomycete Russula lepida. Helv Chim Acta 86: 307-309 (2003)

14. Tan JW, Xu JB, Dong ZJ, Luo DQ, Liu JK. Nigricanin, the firist ellagic acid derived metabolite from the basidiomycete Russula nigricans. Helv Chim Acta 87: 1025-1028 (2004)

15. Zhang J, Feng XZ. Subvellerolactone C, a new lactarane sesquiterpene from Lactarius subvellereus. Chin Chem Lett 7: 1097-1099 (1996)

16. Bernardi MD, Fronza G, Mellerio G, Valla V, Vidari G, VitaFinzi P. Fungal metabolites. XVII. Sesquiterpenes from Lacarius pallidus Persoon. Gazz Chim Itali 114: 163-168 (1984)

17. Daniewski WM, Wawrzun A, Bernardi MD, Vidari G, VitaFinzi P, Fronza G, Gatti G. Structural studies on Lactarius sesquiterpenes: structure elucidation of lactarorufins D and $\mathrm{E}$ and conformational analysis of lactaran-5-olides. Tetrahedron 40: 2757-2762 (1984) 